\title{
CLARICE VAI AO ZOOLÓGICO: NOTAS SOBRE OLHAR E DIFERENÇA ANIMAL ${ }^{1}$
}

\section{CLARICE GOES TO THE ZOO: NOTES ON LOOKING AND ANIMAL DIFFERENCE}

Paula Amparo (PPGCL-UFRJ/CNPq)

paulacgamparo@gmail.com

Gabriel Martins da Silva (PPGLCC-PUC-Rio)

gabrielms8@gmail.com

\begin{abstract}
RESUMO: A escritora Clarice Lispector reservou, ao longo da sua obra, um espaço privilegiado para o encontro entre humanos e animais, através de trocas de olhares que desestabilizam a hierarquia ontológica entre os seres. Em uma argumentação interessada no papel do olhar durante o encontro com a diferença animal, analisaremos os contos " $O$ búfalo", de Laços de Família (1960), e "Tentação", de A legião estrangeira (1964), em diálogo com os trabalhos de Giorgio Agamben e John Berger sobre o lugar social do zoológico como dispositivo de separação, controle e catalogação do que é dado como natureza $e$ cultura.
\end{abstract}

PALAVRAS-CHAVE: Clarice Lispector; olhar; zoológico; animalidade.

ABSTRACT: The writer Clarice Lispector reserved, throughout her work, a privileged space for the encounter between humans and animals, through exchanges of glances that destabilize the ontological hierarchy amid beings. In an argument interested in the role of the gaze during the encounter with animal difference, we will analyze the short stories "O búfalo", from Laços de Família (1960), and "Tentação", from A legião estrangeira (1964), in dialogue with the works of Giorgio Agamben and John Berger regarding the social place of the zoo as a device for separation, control, and the cataloging of what is given as nature and culture.

KEYWORDS: Clarice Lispector; looking; zoo; animality

\footnotetext{
${ }^{1}$ Esse ensaio foi uma reescrita em dupla do quarto capítulo, intitulado "Cartografia afetiva de um zoológico", da monografia Ostras, galinhas e baratas: Devir e diferença em Clarice Lispector, defendida por Gabriel Martins da Silva em 17 de dezembro de 2020 no Departamento de Ciências Sociais da Pontifícia Universidade Católica do Rio de Janeiro, orientada pelo professor Felipe Süssekind e coorientada pela professora Déborah Danowski.
} 
Toda a expressão deles mora nos olhos - e perde-se a um simples baixar de cílios, a uma sombra

Carlos Drummond de Andrade, Claro enigma

Se todo animal inspira ternura, o que houve, então, com os homens? Guimarães Rosa, Ave, palavra

His stride is wildernesses of freedom:

The world rolls under the long thrust of his heel.

Over the cage floor the horizons come.

Ted Hughes, New Selected Poems 1957-1994

Os animais têm um papel central na literatura clariceana, tematizados desde seu primeiro romance, Perto do coração selvagem (1943), até seu último, A hora da estrela (1977). Tema presente, inclusive, em seus livros infantis, publicados já no final de sua vida. Clarice Lispector, segundo Antoneli Sinder (2018, p. 22), estudiosa da produção infantojuvenil da autora, "não parece estabelecer uma separação entre as temáticas que aborda em sua obra para adultos das que propõe para a infância”. Além de serem elementos importantes em sua poética, ao que tudo indica, Clarice teve uma relação próxima com os animais desde sua infância em Recife, como aponta Nádia Gotlib, sua biógrafa: “O casarão velho em que morava era mesmo grande, em Recife, na praça Maciel Pinheiro, onde vai desembocar a rua da Imperatriz. E tinha quintal, onde criava... bichos. Teve um macaco, na infância. E muitos gatos" (GOTLIB, 2013, p. 64). Esse contato precoce e próximo certamente impactou a pequena Clarice, cujo interesse inesgotável pela forma animal foi cultivado durante toda sua vida - evidenciado pela amplitude já mencionada do tema ao longo de sua obra, incontornável também em cartas, contos e crônicas. Em Água viva, Clarice confessa: "Estou precisando estudar bichos" (LISPECTOR, 1998a, p. 48), numa necessidade irremediável de contato com a diferença animal, ou, pelo menos, da investigação de seus mistérios.

Dentro da variedade de textos da autora em que animais aparecem, destacamos dois que serão importantes para a discussão proposta aqui, presentes nos livros de contos Laços de família (1960) e A legião estrangeira (1964): "O búfalo" e "Tentação", respectivamente. Os contos trazem a instituição do olhar enquanto dispositivo de contato entre humanidade e animalidade e, especificamente no primeiro, o zoológico como palco.

Posto isso, o lugar do animal na poética clariceana não é o de apenas mais um elemento entre tantos - como, por exemplo, no encontro entre o basset e a menina, ou entre a mulher de casaco marrom e o búfalo no zoológico, em que tanto o animal quanto o humano se contaminam através do olhar, desestabilizando, mesmo que por um instante, a fronteira que os 
separa. O animal, ali, ocupa o lugar de uma operação de deslocamento da humanidade, como bem menciona Evando Nascimento em Clarice: uma literatura pensante: "A literatura de Clarice tem ajudado a questionar os limites do humano, na medida mesma em que traz para seu espaço formas concorrentes em relação à tradição, tais como animais e objetos, texturas, paisagens, cores, trechos musicais, ruídos e silêncios" (NASCIMENTO, 2012, p. 25). Os dois contos escolhidos para estas notas têm em comum essa disposição das personagens (ambas mulheres) para o encontro com esta alteridade radical (um cachorro e um búfalo), em que as duas duplas de humanos-animais são descritas pelos narradores como pares, metades, como prometidos um para o outro: "sua outra metade neste mundo" (LISPECTOR, 1999, p. 61), diz a narradora de "Tentação" sobre o encontro entre o basset e a menina ruiva; e "Oh, Deus, quem será meu par neste mundo?” (LISPECTOR, 2009, p. 128), indaga a personagem de "O búfalo".

A literatura de Clarice Lispector, portanto, projeta uma zona de exceção, na qual o animal pode assumir um lugar diferente daquele reservado pela tradição. Ao assumir formas diversas, pode dar conta da multiplicidade de sentidos contidos no substantivo "animal", como lembra Nádia Gotlib:

\begin{abstract}
Além de gatos e galinhas [...] [,] o cachorro italiano Dilermando, o cachorro americano Jack, a miquinha Lisete [...] [,] a rata Maria de Fátima, o cão Bruno Barbieri de Monteverdi e a cadela Bolinha. [...] coelhos, leão, girafa, macacos, peixes, búfalos, baratas, pombos, lagartixa, pintos, periquitos, ratos, cavalos, patos, quati, cães (GOTLIB, 2013, p. 66).
\end{abstract}

Interessante notar, desde já, como a construção do termo o animal - no singular genérico, com artigo definido - é fruto de uma arbitrariedade. Poderíamos nos reportar às diversas hipóteses que procuram justificar essa divisão entre humano e animal - que logo nos remete àquela entre natureza e cultura, uma outra cisão igualmente importante - , porém o questionamento salutar a ser feito aqui é de que forma o animal se estabeleceu como um "conceito que serve para qualquer coisa [...] [no qual] seriam encerrados [...] todos os viventes que o homem não reconheceria como seus semelhantes", conforme escreve o pensador francês Jacques Derrida (2002, p. 64-65) em seu livro O animal que logo sou, reunião de textos e falas proferidas em Cerisy-la-Salle acerca da questão do animal na filosofia moderna e contemporânea. Uma espécie (humana) se defronta com toda uma multiplicidade de seres radicalmente distintos entre si e, entretanto, define-se por uma oposição única a toda essa multiplicidade. Essa divisão, por óbvio, não é de todo inocente, já que carrega, mesmo em sua origem - difícil de determinar, existindo desde a antiguidade —, uma valoração moral, 
marcando o nascedouro do dito excepcionalismo humano. Com isso, Derrida, nesse gesto de "problematização" de um suposto animal universal, irá recorrer a exemplos pertinentes para desconstruir o animal enquanto conceito, produzido "apesar dos espaços infinitos que separam o lagarto do cão, o protozoário do golfinho, o tubarão do carneiro, o papagaio do chimpanzé, o camelo da águia, o esquilo do tigre ou o elefante do gato, as formigas do bichoda-seda ou o ouriço da equidna" (DERRIDA, 2002, p. 70).

Kuniichi Uno, ex-aluno de Deleuze e seu tradutor para o japonês, em seu livro sobre o dançarino butô Hijikata Tatsumi escreve sobre as dificuldades de se abordar autores canônicos, nos quais a fortuna crítica já se deteve bastante, com muitos ensaios, acúmulos, fantasmas e clichês:

Como sempre acontece com os criadores fundamentais [...] aparecem inevitavelmente os fantasmas, os mal-entendidos, os clichês, as recuperações simplistas, as idolatrias falsificadoras e as escavações acadêmicas. Eu não pretendo oferecer uma imagem real ou autêntica desse criador [...]. A meu ver, seus enigmas habitam outros enigmas (UNO, 2018, p. 14).

Assim como Tatsumi no Japão, Clarice Lispector tornou-se cânone no Brasil, com uma vasta produção acadêmica sobre sua obra - que aumenta a cada ano, inclusive, com a internacionalização de sua literatura. O movimento proposto nestas notas foi, a partir do encontro de olhares entre o humano e o animal em Clarice, tentar fugir dos clichês sobre sua obra, além de não tentar "resolver" ou "iluminar" os enigmas e aporias de seus textos. O impulso foi o de habitar os problemas sem, com isso, resolvê-los. Deixar-se levar pelos mistérios e paradoxos sem uma culminância - ou pelo menos que a culminância, caso haja, nos leve a outras aporias.

\section{1.}

O zoológico como ambiente de estranhamento e de contato com a alteridade já aparece antes mesmo da publicação do primeiro romance de Clarice Lispector. Em carta a Lúcio Cardoso em julho de 1941, a escritora conta como foi sua chegada e recepção em Belo Horizonte e, para ilustrar esse quadro, acrescenta: "As pessoas daqui me olham como se eu tivesse vindo direto do Jardim Zoológico. Concordo inteiramente" (LISPECTOR, 2002, p. 15). Por exemplo, em A hora da estrela, Macabéa e Olímpico, seu namorado, fazem uma visita ao zoológico. Os dois sentimentos que afloram na troca de olhares com os animais durante aquele passeio são o medo e o espanto - certamente, afetos que atravessam toda a literatura de Clarice. "Teve muito espanto ao ver os bichos. Tinha medo e não os entendia: 
por que viviam?” (LISPECTOR, 1998b, p. 55), elucida Rodrigo, narrador em terceira pessoa do romance, e continua: "Teve tanto medo que se mijou toda" (LISPECTOR, 1998b, p. 55), tamanho era o espanto e o efeito que aqueles animais tinham sobre o corpo da personagem aliás, sem deixar de ressaltar, de uma grande violência. O mesmo espanto que sente a mulher de casaco marrom em "O búfalo" ao se frustrar no zoológico: "Ela que poderia ter aproveitado o grito dos outros para dar seu urro de lamento, ela se esqueceu, ela só teve espanto" (LISPECTOR, 2009, p. 129). Espanto e medo se inscrevem, antes de mais nada, no corpo dessas personagens, condição de possibilidade desse contato com a diferença animal, como bem aponta Marília Librandi (2012, p. 190): "para entender o ponto de vista de outrem é preciso assumir seu corpo, "encorporá-lo"'.

"O búfalo" conta a história de uma mulher que - assim como Macabéa — vai ao zoológico, mas neste caso em busca de algo que potencialize seu ódio após ter sido recusada por seu pretendente. A atmosfera do conto enfatiza o acasalamento dos animais, um convite à vida amorosa, ao acolhimento. Tudo aquilo que a personagem não deseja. Diante dos olhares de diversos animais - leões, girafas, hipopótamos, macacos, elefantes, camelos -, a mulher não consegue encontrar aquilo que procura; pelo contrário, a nudez, o amor, a leveza, a docilidade, a ingenuidade e a paciência são as respostas dadas pelos animais, frustrando a cada vez suas expectativas. Ao se deparar com o búfalo, seu par, ela é inundada por um sentimento ambíguo, que apesar de já existente, chega a um limite na troca de olhares com o animal: "Eu te amo, disse ela então com ódio" (LISPECTOR, 2009, p. 134), e mais adiante, "Eu te odeio, disse implorando amor ao búfalo" (LISPECTOR, 2009, p. 134). Nesse quiasma se cruzam a profunda indiferença do búfalo e, na mulher, este instante de paradoxal mistura afetiva em que amor e ódio se contaminam reciprocamente. Escreve Patrícia Vieira (2020, p. 120) sobre esse instante: "Dentro do regime escópico que governa o zoológico, local onde os humanos vão observar os animais, o búfalo é o único ser vivo que 'encarna' [...] a mulher e devolve o olhar". Os dois se aproximam a ponto de apenas a grade os separar. A separação (a fronteira) entre esses dois seres radicalmente diferentes, a cisão entre a natureza e a cultura, entre o animal e o humano, reduzem-se aí a essa única materialidade. Os dois se pertenciam, contaminavam-se mutuamente. "Os papéis prefixados se intertrocam ${ }^{2}$, retirando a capa de predeterminação do sentir exclusivo, ou bem humano, ou bem animal”, escreve Evando

\footnotetext{
${ }^{2} \mathrm{O}$ verbo intertrocar aparece em outros momentos na obra de Clarice Lispector, como, por exemplo, em $A$ hora da estrela, para descrever a relação imbricada e interdependente entre o narrador, Rodrigo, e a personagem Macabéa.
} 
Nascimento (2012, p. 33). Houve ali, mesmo que por um momento apenas, uma instabilidade na fronteira a que Derrida se referia.

O búfalo não fala. O único contato possível é através dos olhos: "Ela não olhou a cara, nem a boca, nem os cornos. Olhou seus olhos. E os olhos do búfalo, os olhos olharam seus olhos" (LISPECTOR, 2009, p. 135), como um ser ontologicamente equivalente à mulher. Tomada por uma náusea tonteante, "lentamente a mulher meneava a cabeça, espantada com o ódio, a olhava" (LISPECTOR, 2009, p. 135), consciente de que estava lidando com algo que a afetava violentamente. Nesse encontro contingente e desconfortável, diante do limite da linguagem, a troca de olhar com o búfalo revela um encontro que destitui a mulher da posição de sujeito humano. Ao sentir "ódio" através da reciprocidade do olhar, surge uma zona de comunicação que não é nem humana ou animal, mas que se passa entre a mulher e o búfalo.

Em texto publicado na seção "Fundo de gaveta", intitulado "A explicação inútill", Clarice escreve algumas notas sobre o pontapé inicial da escritura de contos - algo pouco recorrente nos registros arquivísticos da escritora:

\begin{abstract}
"O búfalo" me lembra muito vagamente um rosto que vi numa mulher ou em várias, ou em homens; e uma das mil visitas que fiz a jardins zoológicos. Nessa, um tigre olhou para mim, eu olhei para ele, ele sustentou o olhar, eu não, e vim embora até hoje. O conto nada tem a ver com tudo isso, foi escrito e deixado de lado. Um dia reli-o e senti um choque de mal-estar e horror (LISPECTOR, 2016, p. 646).
\end{abstract}

Acerca dessa passagem metatextual, Nádia Gotlib identifica um fenômeno curioso (por vezes raro) de encontro - ou, por que não, de colapso - entre Clarice-autora e Clariceleitora:

A leitora já se desprendera da escritora. E como leitora, passa pela experiência de choque a que estão sujeitos esses leitores, ela mesma 'presa' nessa rede diabólica de enredar a personagem [...] para o terrível mundo em que aflora o ódio e em que o amor coexiste, igualmente poderoso, submerso (GOTLIB, 2013, p. 409-410).

É como se o feitiço tivesse se voltado contra a feiticeira. Esse efeito ${ }^{3}$ nauseante e de espanto é agora experimentado pela própria autora, traduzido no horror e no mal-estar que a atravessam a partir dessa imagem do "choque" — remetendo ao som e à plasticidade dos raios em uma tempestade. Esse abalo entre escritora e leitora - que lê de tudo, diga-se de passagem: de revistas de bancas de jornal a Proust - apontam para esse atravessamento, no qual Clarice não resiste a si mesma, conforme nota que abre Uma aprendizagem ou O livro dos prazeres, de 1969: "Eu sou mais forte do que eu" (LISPECTOR, 1998c, p. 9).

\footnotetext{
${ }^{3}$ Presente em suas personagens e que tem seu ápice em A paixão segundo G.H. de 1964, já identificado por grande parte de seus leitores como sensação sempre presente na leitura árdua dos textos.
} 
John Berger, crítico de arte inglês, em "Por que olhar os animais?”, traça um panorama do contato entre humanos e animais ao longo da história - desde a origem da linguagem humana e sua relação intrínseca com um mundo compartilhado com os animais, passando pela figura animal como tema na acepção da pintura enquanto domínio humano, os gregos e outras civilizações, como os Nuer (a partir da etnografia do antropólogo Evans-Pritchard), até a formação do totemismo estudado por Lévi-Strauss. O texto tenta dar conta, a partir do chamado cânone clássico (Homero e Aristóteles são exemplos), das transformações desta relação sempre complexa entre humanidade e animalidade até seu desdobramento mais contemporâneo, sintetizado - e, por que não, metaforizado - na imagem dos zoológicos modernos. Partindo da fundação de três diferentes instituições - o zoológico de Berlim (1844), o de Londres (1828) e o Jardin des Plantes (1793) em Paris -, Berger assume que elas "eram uma confirmação do poder colonial moderno" (BERGER, 2003, p. 26) no século XIX, a partir do sentido que esses espaços tomaram no decorrer da formação industrial dos países europeus, da expansão da malha urbana e do consequente impacto desse estilo de vida moderno sobre o tecido social e sua fronteira com o mundo animal. A captura de animais era a representação simbólica da conquista de todos os países exóticos e remotos: “"Exploradores’ provavam seu patriotismo mandando para casa um tigre ou um elefante. O presente de um animal exótico ao zôo da metrópole tornou-se um símbolo nas relações diplomáticas subservientes" (BERGER, 2003, p. 26) ${ }^{4}$. E continua Berger:

Zoológicos públicos surgiram no começo do período em que os animais foram desaparecendo da vida cotidiana. O zoológico no qual as pessoas vão ver animais, observá-los, é na verdade um monumento à impossibilidade de tais encontros. Zoológicos modernos são um epitáfio a uma relação tão antiga quanto o próprio homem (BERGER, 2003, p. 26).

Em sintonia com a hipótese de Berger, Eneida Maria de Souza, professora emérita da Universidade Federal de Minas Gerais, em "De animais e de literatura: Rosa, Kafka e Coetzee", traça essa genealogia da instituição do zoológico em diálogo com o espírito da época, que marcava as relações entre sociedade de massa e entretenimento, ciência e colonialismo:

Fruto do imperialismo expansionista, do exotismo como símbolo da diferença e da

\footnotetext{
${ }^{4}$ Para além dessa constatação do papel dessas instituições na formação urbana da modernidade europeia, vale ressaltar a ambiguidade dos zoológicos. Como aponta Juliana Fausto (2017, p. 101): "Desde o seu surgimento, os zoológicos gozam de uma ambígua vocação, sendo lugares de entretenimento saudável e instrutivo para os cidadãos, de estudos científicos e símbolos de grandeza nacional”.
} 
dominação antropocêntrica da raça branca, os zoológicos europeus atuavam como contrapartida popular e de massa ao discurso da ciência. Espetáculo, ciência e literatura se aproximam e se contrapõem, ao dirigirem olhares diferentes aos animais, ao transmitirem saberes que reiteram e deslocam visões da cultura frente à natureza (SOUZA, 2011, p. 83).

Portanto, o progressivo distanciamento - físico e simbólico - entre humanos e animais veio acompanhado de algumas transformações significativas: a proliferação de animais de estimação, sexualmente isolados e esterilizados; a cooptação desses animais pela indústria de massa a partir das produções Disney, na qual práticas sociais habituais são projetadas no reino animal; a produção de animais de brinquedo cada vez mais verossimilhantes; e, por último, a invenção dos zoológicos modernos. Esses são os vetores que marcam a relação de distância - e de ambígua proximidade, no caso dos zoológicos entre humanos e animais na vida moderna. A hipótese que norteia Berger é a de que "zoológicos, brinquedos animais realistas e a difusão comercial ampla da imagística animal, tudo isso iniciou quando os animais começaram a ser afastados da vida cotidiana" (BERGER, 2003, p. 29-31). Existe aqui uma relação possível entre esse caráter paradoxal de aproximação distante entre humanos e animais e a posição delicada da personagem de " $\mathrm{O}$ búfalo" diante dos animais enjaulados: se, por um lado, eles são separados pelas grades do zoológico, por outro, eles se pertencem; ou ainda, por mais distante que aqueles animais estejam da mulher, por mais opaco que seja o corpo daqueles animais, é apenas a grade, sua materialidade risível, que os separa.

Em consonância com esse breve panorama social sobre a instituição do zoológico como espaço da legitimação do poder colonizador, cito Juliana Fausto, especialista em filosofia política e animalidade, em sua tese de doutorado intitulada A cosmopolítica dos animais, que comenta as observações feitas por Brian Massumi(2014), em seu What Animals Teach us about Politics?, sobre Gregory Bateson (2000), sublinhando a importância das grades nos cativeiros de zoológicos:

Qual é a mensagem metacomunicativa que algo tão concreto como grades de ferro
passam? Qual é a relação entre figura e fundo em uma exibição de animais cativos
diante de humanos? Dentro dos recintos [...] encontra-se a natureza; do lado de fora,
a cultura. Os animais em exposição em um zoológico proveem o pano de fundo -
que é visto, mas com o qual qualquer interação de mão dupla é interditada - para os
sujeitos humanos. As grades, cercas, jaulas, telas de metal são o enquadre concreto
que informa: daqui para dentro, a animalidade; daqui para fora, a humanidade.
Trata-se assim de um procedimento de "exclusão por inclusão", a animalidade
contida dentro do mundo humano significando aquilo que ele não é (COUTINHO,
2017, p. 95).

É neste sentido que Berger (2003, p. 31) afirma que “o objetivo dos zoológicos é oferecer aos visitantes a oportunidade de olhar animais. Mas em parte alguma num zoológico 
o visitante pode encontrar o olhar de um animal [...] Foram imunizados contra o encontro" e, dessa forma, “o zoológico só pode decepcionar" (BERGER, 2003, p. 31). Os dispositivos de separação em jogo nos zoológicos operariam como a "máquina antropológica dos modernos" (AGAMBEN, 2013, p. 58), descrita pelo filósofo italiano Giorgio Agamben em $O$ aberto - O homem e o animal, a partir das descobertas e contradições de Heymann Steinthal sobre as origens da linguagem humana - marco decisório para a distinção do humano como espécie excepcional, ou seja, com atributos próprios e extraordinários. Referindo-se a Steinthal, segundo Agamben (2013, p. 61) “está em jogo a produção do humano, por meio da oposição homem/animal, humano/inumano, a máquina funciona necessariamente por meio de uma exclusão (que é já [...] uma captura) e uma inclusão (que é também uma exclusão)". Ou seja, “o humano já é, com efeito, o pressuposto ${ }^{5}$, a máquina produz na realidade um tipo de estado de exceção, uma zona de indeterminação na qual o fora não é a exclusão de um dentro e o dentro, por sua vez, tampouco é a inclusão de um fora" (AGAMBEN, 2013, p. 61). Assim, para o filósofo italiano, Steinthal "buscava compreender [...] por que apenas o homem, e não o animal, cria a linguagem; mas isso significava compreender de que modo o homem se origina a partir do animal” (AGAMBEN, 2013, p. 60). Dessa maneira, e em interlocução com Berger, "os visitantes vêm ao zoológico para olhar os animais. Passam de jaula em jaula como visitantes de uma galeria de arte param na frente de um quadro, depois de outro e outro. Mas no zoológico a visão é sempre errada. Como uma imagem fora de foco" (BERGER, 2003, p. 28).

3.

Sendo assim, a partir da divisão operada pelas grades no zoológico, o animal é supostamente desprovido da capacidade do olhar justamente por não lhe ser permitido se configurar enquanto sujeito. Por isso, segundo Berger, o zoológico só pode decepcionar, uma vez que ele possibilita o visitante olhar algo que está momentaneamente impedido de olhar de volta, imunizado contra o encontro. Digamos que essa condição, apesar de apresentada a partir dos zoológicos, não se limita aos espaços controlados de confinamento dos animais, tendo se fixado como a percepção majoritária do animal na cultura ocidental, dispondo humanidade e animalidade em oposição a partir de critérios hierárquicos. Essa é precisamente

\footnotetext{
5 "Os animais tornam-se 'pessoas' no zoológico por uma operação na qual suas especificidades comportamentais e fisiológicas são negadas em favor de uma identificação com instituições humanas: romances, celebração de feriados, aniversários, nascimentos e também de substituições de animais mortos como se fossem novos parentes em alegre visita" (COUTINHO, 2017, p. 98).
} 
a máquina antropológica de que fala Agamben. Os animais nos zoológicos são sempre as coisas vistas que não veem ${ }^{6}$.

Clarice Lispector, subvertendo essa hipótese, produz o encontro entre humanos e animais no zoológico justamente a partir do olhar. Os olhos, nos dois textos escolhidos neste trabalho, são as portas - um pouco emperradas, fechadas, ou até sem fechadura - para a diferença animal. Clarice, de uma certa maneira, realiza esse encontro a partir do olhar justamente por possibilitar a subjetivação desses animais, por permitir-lhes a configuração como sujeitos. "Era entre os olhos do macaco que ela mataria, era entre aqueles olhos que a olhavam sem pestanejar" (LISPECTOR, 2009, p. 127), escreve Clarice sobre esse desejo de matar, direcionado, através do olhar, para o macaco, cuja resposta, também possível pelo olhar, opera como um quiasma em direção à mulher de casaco marrom. Ou ainda, a partir do mesmo gesto, “de dentro da jaula o quati olhou-a. Ela o olhou. Nenhuma palavra trocada. Nunca poderia odiar o quati que no silêncio de um corpo indagante a olhava. Perturbada, desviou os olhos da ingenuidade do quati. O quati curioso lhe fazendo uma pergunta como uma criança pergunta” (LISPECTOR, 2009, p. 130). Tal movimento permite, através desse olhar antes impossível, por exemplo, que os animais sejam vistos como dotados da faculdade de indagar, de colocar questões - tarefa primordial da filosofia —, e de desestabilizar as afirmações desse "sujeito humano". É como se o quati e o macaco, através desse "corpo indagante", pudessem perguntar o porquê do ódio. Nessa conversa, mesmo que impossível, alguma faísca é lançada, algum mínimo horizonte é desenhado nessa (im)possibilidade tonteante de comunicação. É esse mesmo mecanismo de indagação (im)possível do animal que Derrida parte no relato pessoal em $O$ animal que logo sou. O filósofo nu se depara com o olhar de seu gato - aquele que, desde sempre, não olha - e esse olhar do gato lhe possibilita enxergar o trespassamento das fronteiras entre humano e animal. Indaga Derrida (2002, p. 30) diante desse acontecimento: "Que me dá a ver esse olhar sem fundo? Que me 'diz' ele que manifesta em suma a verdade nua de todo olhar, quando essa verdade me dá a ver nos olhos do outro, nos olhos vendo e não apenas vistos pelo outro?”.

Partindo de uma análise da voz e do olhar na obra da Clarice Lispector, Júlio Diniz, professor de literatura e especialista na autora, chama isso de "olhar (do) estrangeiro [...] [esse] dispositivo especulativo e desestabilizador" (DINIZ, 2012, p. 72). "Pensar a figura do estrangeiro é tentar localizar alguém imerso no conflituoso campo tradutório das relações afetivas e socioculturais de um outro que é o outro de si”, continua Diniz (2012, p. 73). É, por

\footnotetext{
${ }^{6}$ Escreve John Berger (2003, p. 28): "estaremos olhando algo que se tornou absolutamente marginalizado". 
exemplo, nessa relação com o animal que a personagem de "O búfalo" poderia usar o grito desta alteridade radical (os animais enjaulados do zoológico) para dar corpo ao seu próprio urro de lamento, como se só pudesse ser eu diante de um outro: "Ela que poderia ter aproveitado o grito dos outros para dar seu urro de lamento" (LISPECTOR, 2009, p. 129). $\mathrm{Ou}$, como afirma Diniz, esse outro radical que, no limite, é sempre um outro de si, nãoidêntico, mas profundamente (e estranhamente) familiar. Esse jogo de espelhos é o dispositivo capaz de complicar o lugar da grade no zoológico como trincheira entre humanidade e animalidade. "O olhar do búfalo leva, dessa forma, a mulher ao limite abissal do humano, como se a desvelasse, colocando-a em situação de perda e vertigem”, diz Maria Esther Maciel (2016, p. 86).

\section{4.}

O conto "Tentação", de Clarice Lispector, apresenta alguns elementos interessantes para pensarmos a interlocução com essa instituição do olhar. Publicado na coletânea A legião estrangeira, em 1964, o conto narra o encontro de uma menina com um cachorro basset. De saída, a menina é apresentada como ruiva e com soluço, traços que certamente a identificam enquanto uma exceção em meio àquele mundo, afinal: "Numa terra de morenos, ser ruivo era uma revolta involuntária" (LISPECTOR, 1999, p. 61). Mas é no segundo parágrafo que o olhar aparece como elemento importante da narrativa: "submisso e paciente", ele é entrecortado pelos soluços violentos que abalam o queixo da menina. "O que a salvava era uma bolsa velha de senhora, com alça partida" (LISPECTOR, 1999, p. 61), observa o narrador, elucidando a precariedade tanto da cena quanto da personagem, que está bastante próxima de outras, como Macabéa, que, apesar de pouco terem, são infinitamente felizes. A menina, que "sentada num degrau faiscante" esperava o bonde sob um sol quase insuportável, vê "no ângulo quente da esquina, acompanhando uma senhora", "a sua outra metade neste mundo". Sua outra metade é um cachorro, um basset ruivo, assim como ela exótico, minoritário, uma exceção: “Os pelos de ambos eram curtos, vermelhos” (LISPECTOR, 1999, p. 62). A descrição do cão é feita a partir de três adjetivos, ainda que o terceiro seja um substantivo deslocado: "Desprevenido, acostumado, cachorro" (LISPECTOR, 1999, p. 61). Esta última característica marca a singularidade daquele ser, que não pode ser capturado, que pode apenas ser olhado. Ao se deparar com o cão ruivo, "a menina abriu os olhos pasmada" (LISPECTOR, 1999, p. 62) enquanto "ambos se olhavam". Assim como em "O búfalo", os 
animais não falam; a única relação possível entre a menina e o basset é através do dispositivo do olhar, quer dizer, a partir de suas diferenças, numa transversalidade que resguarda o animal da máquina antropológica de que falava Agamben: "Ele fremia suavemente, sem latir. Ela olhava-o sob os cabelos, fascinada, séria” (LISPECTOR, 1999, p. 62). Apesar do desejo irresistível da menina de ter aquele cachorro para si, como sua propriedade, o único momento em que aquilo chegaria mais perto de se tornar realidade era no instante mesmo do encontro entre aqueles dois seres. "E no meio de tantas ruas a serem trotadas, de tantos cães maiores, de tantos esgotos secos - lá estava uma menina, como se fora carne de sua ruiva carne. Eles se fitavam profundos, entregues, ausentes de Grajaú" (LISPECTOR, 1999, p. 62). E, em meio àquele equilíbrio quase perfeito, o momento se rompe, e o elo entre os dois é quebrado: "Ambos eram comprometidos", diz o narrador, isto é, pertenciam a mundos diferentes, "ela com sua infância impossível [...] ele, com sua natureza aprisionada" (LISPECTOR, 1999, p. 62). "O basset ruivo afinal despregou-se da menina e saiu sonâmbulo", e ela, "numa mudez que nem pai nem mãe compreenderiam. Acompanhou-o com os olhos", sempre com os olhos, a única possibilidade de se tentar alcançar o animal. Ambos mudos. No desfecho, num ato de frieza quase humano, o basset fora mais forte que a menina: "nem uma só vez olhou para trás” (LISPECTOR, 1999, p. 62).

\section{5.}

Em contos como esses, mas também em outros romances de Clarice, a obra apresentase como um "caleidoscópio multissensorial" (NASCIMENTO, 2012, p. 78), no qual "o olhar é somente um dispositivo para desencadear inúmeras outras sensações e pulsações" (NASCIMENTO, 2012, p. 79). Ainda sobre esse olhar, em Um sopro de vida (Pulsações), diz o personagem-narrador do texto:

\footnotetext{
Descobrir uma nova maneira de viver. [...] O resultado de um processo tão novo de olhar o momento que passa seria muitas vezes estranhar uma coisa como se pela primeira vez a víssemos. [...] Há um encontro meu e dessa coisa vibrando no ar. Mas o resultado desse olhar é uma sensação de oco, vazio, impenetrável e de plena identificação mútua (LISPECTOR, 1978, p. 91).
}

Mesmo com a opção de Clarice por privilegiar o olhar (do) estrangeiro enquanto dispositivo para o encontro entre humanidade e animalidade, há uma multiplicidade de maneiras do animal habitar a escritura: a barata encontrada no quarto de empregada em $A$ paixão segundo G.H., ou as baratas que invadem a cozinha na madrugada em "A quinta história"; a menina e a galinha em "Uma galinha", ou as galinhas Eponina, Petrilha e Pedrina 
em "Uma história de tanto amor"; o inseto e a aranha em "Uma esperança"; o rato em "Perdoando Deus"; ou ainda a macaca Lisette, mulher em miniatura, em "Macacos".

As perguntas desestabilizadoras "elaboradas" pelos animais nesses dois contos, só possíveis a partir do olhar (im)possível (do) animal, são também as perguntas que mobilizam, num certo sentido, Clarice Lispector. As respostas procuradas - e não dadas - são o motor de diversos autores que buscam, no animal, a fonte primária de sua escrita. E a respeito das perguntas feitas sobre o que sabem dos humanos os animais, escreve Maria Esther Maciel (2016, p. 86): "Não há resposta satisfatória. Do que sabem os animais sobre os humanos ninguém sabe, mas tudo se imagina. E toda tentativa de se revelar esse saber está condenada ao fracasso, o que, entretanto, não impede que os escritores continuem conjecturando sobre esse possível saber”. Em Água viva, Clarice escreve sobre o que está em jogo no entrecruzamento de olhares com o animal: "Arrepio-me toda ao entrar em contato físico com bichos ou com a simples visão deles. Os bichos me fantasticam" (LISPECTOR, 1998a, p. 48). O contato estabelecido a partir do olhar, inscrito no corpo - como é o contato com toda diferença animal - é uma das chaves para lermos tanto os textos de Clarice como para repensarmos a relação entre humanos e animais. É ao arrepio que invade o corpo da escritora em Água viva, o da mulher de casaco marrom em "O búfalo", ou ainda o de Macabéa em sua visita ao zoológico que precisamos nos ater, ao nos demorarmos olhando os mínimos detalhes selvagens - e ao mesmo tempo familiares - que podem nos fantasticar, para parafrasear a própria Clarice.

\section{REFERÊNCIAS}

AGAMBEN, G. O aberto - O homem e o animal. Rio de Janeiro: Civilização Brasileira, 2013.

ANDRADE, C. D. de. Claro enigma. São Paulo: Companhia das Letras, 2012.

BATESON, G. A Theory of Play and Fantasy. In: BATESON, G. Steps to an Ecology of Mind. Chicago: The University of Chicago Press, 2000.

BERGER, J. Por que olhar os animais? In: BERGER, J. O olhar. Barcelona: GG, 2003. p. 1132.

COUTINHO, J. F. de S. A cosmopolítica dos animais. Tese (Doutorado em Filosofia) Pontifícia Universidade Católica, Rio de Janeiro, 2017.

DERRIDA, J. O animal que logo sou. São Paulo: UNIFESP, 2002.

DINIZ, J. Canção para ninar elefantes - voz, olhar e escrita em Clarice Lispector. In: KIFFER, 
A.; BIDENT, C. Anacronismos. Rio de Janeiro: 7Letras, 2012.

GOTLIB, N. B. Clarice: uma vida que se conta. São Paulo: Ed. da USP, 2013.

HUGHES, T. New Selected Poems 1957-1994. London: Faber and Faber, 2010.

LIBRANDI, M. Escutar a Escrita: Por uma teoria literária ameríndia. O eixo e a roda, Belo Horizonte, v. 21, n. 2, p. 179-202, 2012.

LISPECTOR, C. Água viva. Rio de Janeiro: Rocco, 1998a.

LISPECTOR, C. A hora da estrela. Rio de Janeiro: Rocco, 1998b.

LISPECTOR, C. A legião estrangeira. Rio de Janeiro: Rocco, 1999.

LISPECTOR, C. Correspondências. Org. Teresa Montero. Rio de Janeiro: Rocco, 2002.

LISPECTOR, C. Laços de família. Rio de Janeiro: Rocco, 2009.

LISPECTOR, C. Todos os contos. Org. Benjamin Moser. Rio de Janeiro: Rocco, 2016.

LISPECTOR, C. Uma aprendizagem ou O livro dos prazeres. Rio de Janeiro: Rocco, 1998c.

LISPECTOR, C. Um sopro de vida (Pulsações). Rio de Janeiro: Nova Fronteira, 1978.

MACIEL, M. E. Literatura e animalidade. Rio de Janeiro: Civilização Brasileira, 2016.

MASSUMI, B. What Animals Teach us about Politics? Durham: Duke University, 2014.

NASCIMENTO, E. Clarice Lispector: uma literatura pensante. Rio de Janeiro: Civilização Brasileira, 2012.

SILVA, G. M. Ostras, galinhas e baratas: Devir e diferença em Clarice Lispector. Trabalho de Conclusão (Bacharelado em Ciências Sociais) - Pontifícia Universidade Católica, Rio de Janeiro, 2020.

SINDER, A. M. B. Ficções de infância: Clarice Lispector. Rio de Janeiro: Ed. PUC-Rio; Numa Editora, 2018.

SOUZA, E. M. De animais e de literatura: Rosa, Kafka e Coetzee. Aletria, Belo Horizonte, v. 21, p. 83-90, 2011.

UNO, K. Hijikata Tatsumi: Pensar um corpo esgotado. São Paulo: n-1 edições, 2018.

VIEIRA, P. A literatura interespécie de Clarice Lispector. In: COUTINHO, F.; ALENCAR, S. (Org.). Visões de Clarice Lispector: ensaios, entrevistas, leituras. Fortaleza: Imprensa Universitária, 2020.

Artigo submetido em: 31 jul. 2021

Aceito para publicação em: 16 out. 2021

DOI: https://dx.doi.org/10.22456/2238-8915.117291 